\title{
O DISCURSO RELATADO COMO FORMA DE POSIÇÃO IDENTITÁRIA NO GÊNERO MONOGRÁFICO: REFLEXÕES PARA A ATIVIDADE DE REVISÃO DE TEXTOS
}

Jairo Venício Carvalhais Oliveira - FALE/UFMG ${ }^{1}$

\section{INTRODUÇÃO}

Um dos maiores desafios dos estudantes universitários diz respeito ao processamento de textos acadêmico-científicos. Para vencer esses desafios, muitas vezes, os estudantes recorrem a instrumentos didáticos que os auxiliem, sobretudo, na produção desses textos. No entanto, o funcionamento discursivo de textos acadêmico-científicos, como, por exemplo, a monografia exigida para conclusão de cursos de graduação, não tem sido um tema abordado nos diversos manuais de metodologia científica ${ }^{2}$ que circulam nas universidades. Tais obras têm se pautado na estrutura convencional de gêneros como resumo, resenha, artigo, projeto, monografia, entre outros, com vistas a possibilitar a formulação de um conjunto de regras que organizam a produção desses gêneros. Em geral, a primeira preocupação dos autores desses compêndios é a questão do método e da forma. Evidenciam a forma, o recipiente ao qual deve acomodar-se o conteúdo, a ciência, o conhecimento. No entanto, essas obras são pouco adequadas se consideramos que a "normatização de produção de gêneros acadêmico-científicos não contempla a heterogeneidade das práticas discursivas que os engendram" (DIAS, 2005, p. 90). Para a autora, em detrimento de um aparato puramente técnico de construção da escrita acadêmica, são deixadas à sombra orientações que poderiam voltar-se para

\footnotetext{
${ }^{1}$ Mestrando em Lingüística do Texto e do Discurso pelo Programa de Pós-Graduação em Estudos Linguísticos da FALE/UFMG.

${ }^{2}$ Dentre os manuais de metodologia científica a que recorremos, alguns se destacam por privilegiarem o método e a forma da escrita acadêmica. Essas obras estão relacionadas na seção de "Referências bibliográficas", ao final deste artigo.
} 
as questões relativas ao recurso de outrem que prevêem modos de discursivização distintos e, dessa maneira, efeitos enunciativos e polifônicos diferentes.

É possível observar, no exercício de revisão de textos acadêmico-científicos, a pouca familiaridade dos alunos com as práticas prestigiadas de uso da língua escrita no mundo acadêmico. Entre as dificuldades apresentadas pelos alunos, ressalta-se a que diz respeito à inabilidade de operar com os mecanismos enunciativos que envolvem o gerenciamento de vozes no uso do discurso relatado (discurso direto e discurso indireto). Em relação a essa dificuldade, é interessante apresentar questões que parecem ser problemáticas. Por um lado, as obras de metodologia científica são, geralmente, utilizadas como único material de referência para o ensino de escrita na produção de textos pertencentes ao gênero monográfico, mais especificamente, quanto às diferentes formas e funções de materialização do discurso do outro. Esses materiais objetivam apenas refletir sobre as características formais - organização textual e normas de produção acadêmicas dos gêneros que são consumidos e produzidos na universidade. Por outro, vale ressaltar que há obras atuais que visam a suprir as lacunas deixadas pelos materiais de metodologia científica, como, por exemplo, Machado et alli, (2004, 2005), MottaRott (2001), mas, ainda assim, não contemplam a heterogeneidade dos gêneros acadêmicos, tendo em vista as áreas em que eles se atualizam. Em outras palavras, é necessário considerarmos a plasticidade dos gêneros, pois eles são sensíveis aos suportes, aos domínios discursivos em que se atualizam, às estratégias discursivas dos interlocutores, enfim, à enunciação - ato único e jamais repetido de enunciado (Benveniste, 1989 [1966]). Nessa linha de raciocínio, pode-se afirmar que o objeto do discurso das diferentes áreas do conhecimento não é o mesmo, o que motiva, portanto, modos de dizer distintos nos diferentes níveis de texto.

Com base nessas perspectivas, o presente artigo tem como propósito analisar as estratégias de textualização do discurso relatado no gênero monográfico, a partir do estudo da seção de "Fundamentação Teórica" de monografias produzidas como trabalho de conclusão de curso nas áreas de Direito e Psicologia, a fim de demonstrar que a referência ao discurso do outro apresenta formas e funções variadas, caracterizando, portanto, práticas identitárias assumidas e atribuídas aos sujeitos que se formam nessas diferentes áreas. 
A escolha do gênero monográfico se justifica por ser um recurso eficiente para investigar o contato inicial do aluno escritor com o saber científico, bem como para averiguar as diversas maneiras de uso de outras vozes nos textos que produz. Além disso, há inúmeras outras razões, entre as quais destacamos as seguintes: (i) a grande maioria das instituições de ensino superior no país, sejam públicas ou privadas, exige de seus alunos a elaboração de uma monografia como trabalho de conclusão de curso (TCC), principalmente na modalidade de bacharelado; (ii) a monografia não representa uma simples produção de texto, mas um processo de escrita elaborado e reflexivo, passível de uma revisão textual que ultrapasse os níveis estritamente técnicos, o que pode abrir um vasto campo de trabalho para os profissionais que atuam na área de revisão; (iii) trata-se de um gênero discursivo que implica o domínio de diversas práticas acadêmicas, tais como resumir, resenhar e fichar, isto é, atividades de retextualização de textos teóricos, o que permite uma observação do trabalho dos alunos escritores frente às múltiplas vozes que perpassam a escrita do gênero monográfico.

\section{O DISCURSO DO OUTRO: ALGUMAS REFLEXÕES}

O outro se faz presente em todo discurso. O que ouvimos, falamos e, mais precisamente, o que escrevemos, está sempre incorporado de outros dizeres. Seguindo este princípio de alteridade, as práticas de produção da escrita acadêmica fazem constante referência ao discurso do outro de diversas formas e com diferentes finalidades. Isso requer dos alunos escritores uma considerável habilidade no que diz respeito aos modos de retextualização de textos teóricos, a partir da qual eles constroem a sua escrita monográfica.

Em outras palavras, é possível afirmar que o recurso ao discurso do outro pode revelar o modo como o aluno escritor opera no processo de retextualização na academia. Sobre esse assunto, vale destacar as palavras de Matencio: 
Pode-se dizer que o recurso ao discurso do outro tem nas práticas acadêmicas, i) tanto a função de indicar o conhecimento que se tem do campo teórico, o qual fundamenta a seleção ou não de autores com os quais interagir e/ou basear, quanto a função de ii) mostrar a adesão ou não ao(s) autor(es) com o(s) qual(is) dialoga. (MATENCIO, 2003 p. 03)

Pensando nessas funções de utilização do discurso do outro, verifica-se que sua identificação se dá através do jogo polifônico manifestado na materialidade textual, por meio de várias formas linguísticas, denominadas de mecanismos enunciativos, os quais vão marcando a presença de vozes no texto. Segundo Bronckart (1999, p. 319), esses mecanismos contribuem para esclarecer os posicionamentos enunciativos no texto a partir de questões como "quais são as instâncias que assumem o que é enunciado no texto? Quais as vozes que aí se expressam? E traduzem as diversas avaliações (julgamentos, opiniões, sentimentos)". As vozes atuam no texto como entidades, sobre as quais são atribuídas responsabilidades ao enunciado.

Nessa perspectiva, os mecanismos enunciativos são aspectos essenciais no processo de retextualização, pois orientam o produtor na construção do novo texto. Esses mecanismos revelam o diálogo entre o aluno escritor e o autor do texto-base, caracterizando um processo polifônico através do qual se manifesta a multiplicidade de vozes contidas nos textos de cunho acadêmico-científico.

Considerando a marcação explícita e implícita das vozes no texto, Matencio e Silva (2003, p. 12) chamam de estratégias discursivas a citação, a alusão, a evocação, o discurso direto, o discurso indireto, o discurso indireto livre, as modalizações, a ironia, a imitação, a paráfrase. Esses são alguns dos principais mecanismos enunciativos que demonstram a forma como o aluno escritor gerencia as vozes no texto que produz, compreendendo assim "estratégias reveladoras tanto da voz do outro como da voz daquele que assume a autoria do discurso em atualização".

Levando-se em consideração a variedade de formas de referência ao discurso do outro, conforme destacadas por Matencio e Silva (2003, p. 12), Maingueneau (2001) chama-nos a atenção quanto aos procedimentos de maior frequência na realização de citações em textos escritos: o discurso direto e o discurso indireto. Segundo esse autor, o primeiro não mantém estável, em sua globalidade, o conteúdo do discurso citado, pois é a interpretação de um discurso 
anterior, e não a sua reprodução. Por reconstruir, não uma sequência de palavras, mas o conteúdo proposicional do texto-fonte, o discurso indireto resulta na imbricação das palavras do sujeito que cita com as do sujeito citado. A interpretação feita pelo locutor no discurso indireto geralmente resulta na síntese do enunciado citante, suprimidas suas particularidades expressivas.

Já o discurso direto é uma espécie de teatralização de uma enunciação anterior. Essa forma de retratar a voz do outro não se contenta em eximir o enunciador de qualquer responsabilidade, mas ainda simula restituir as falas citadas e se caracteriza pelo fato de dissociar claramente as duas situações de enunciação: a do discurso citante e a do discurso citado (MAINGUENEAU, 2001).

Mesmo quando o discurso direto relata falas consideradas como realmente proferidas, trata-se apenas de uma encenação visando a criar um efeito de autenticidade. Ao contrário do discurso indireto, em que predomina a interpretação, no discurso direto predomina a repetição, a imitação. Ele dá a segurança que decorre da ilusória sensação de exatidão das citações. Essa impressão é suscitada pela presença de particularidades expressivas que seriam correspondentes a uma instância enunciativa preliminar e à configuração de uma situação de comunicação diferenciada da que vigora para o texto em curso.

Nas palavras de Ducrot (1987, p. 156), a diferença entre o discurso direto e o indireto não é que o primeiro daria a conhecer a forma e, o segundo, o conteúdo. $O$ discurso direto também pode visar só ao conteúdo, mas, para fazer saber qual é esse conteúdo, escolhe dar a conhecer uma fala imputada a um locutor. É suficiente que este manifeste efetivamente certos traços salientes da fala relatada, já que o estilo implica fazer falar um outro, atribuir-lhe a responsabilidade da fala; isto nem sempre significa que sua verdade necessite ter uma correspondência literal.

Benites (2002) afirma ser equivocado o julgamento de que o discurso direto é exatamente fiel ao texto original. Para essa autora, não se deve esquecer, ainda, que o deslocamento contextual pode alterar o sentido da transcrição mais exata. Um exemplo desse fato são as epígrafes, nas quais se reproduz um texto ou um fragmento deste, mas não perfeitamente seu sentido original: nelas costuma haver um jogo de vozes entre o locutor que cita e o locutor citado, e a interferência do 
novo enquadramento textual permite satisfazer um certo manejo de seu significado.

Similarmente, no discurso indireto, o locutor citante, como um tradutor que faz uso de suas próprias palavras para transmitir ideias de outro, passa a impressão de ser um simples porta-voz a serviço da transmissão neutra do sentido de uma mensagem anterior. Essa impressão, nas palavras de Benites (2002), também é falsa, na medida em que o locutor seleciona do discurso do outro "o trecho que lhe interessa, submete-o a um filtro próprio e adapta-o a seus objetivos”.

Diante dessas colocações, observa-se que tanto o discurso direto quanto o discurso indireto podem ser manipulados pelo locutor citante (neste caso o aluno escritor da monografia) e empregados segundo o propósito comunicativo de tratar da citação como uma estratégia eleita previamente.

\section{MODOS E FUNÇÕES DE REFERÊNCIA AO DISCURSO DO OUTRO}

Como vimos anteriormente, existem formas variadas de referência ao discurso do outro. Vale ressaltar que, durante o processo de retextualização, o aluno escritor precisa saber gerenciar essas outras vozes que se manifestam no texto produzido, de forma a construir sua monografia não unicamente com as ideias dos autores do texto-base, mas realizando um imbricamento dessas vozes. Dito de outra forma, o aluno escritor não pode se apropriar do discurso do textofonte de forma a apagar sua própria enunciação, mas, antes, deve propor um entrelaçamento de vozes que se agrupam para formar o todo textual.

Do que foi dito até o momento, e, levando em conta as diferentes formas em que o discurso do outro pode ser materializado no novo texto, Boch \& Grossmann (2002), em estudo realizado a respeito de textos de profissionais e de estudantes franceses, apontam que, na escrita teórica, os modos de referência ao discurso segundo são variados, sendo a citação somente uma dentre outras formas, (sem dúvida, a mais explícita de assinalar que o sujeito escritor se apóia no discurso do outro). Abaixo, reproduzimos integralmente o esquema adotado pelos autores 
(Boch \& Grossmann, 2002, p. 100), o qual apresenta a tipologia de referência ao discurso do outro:

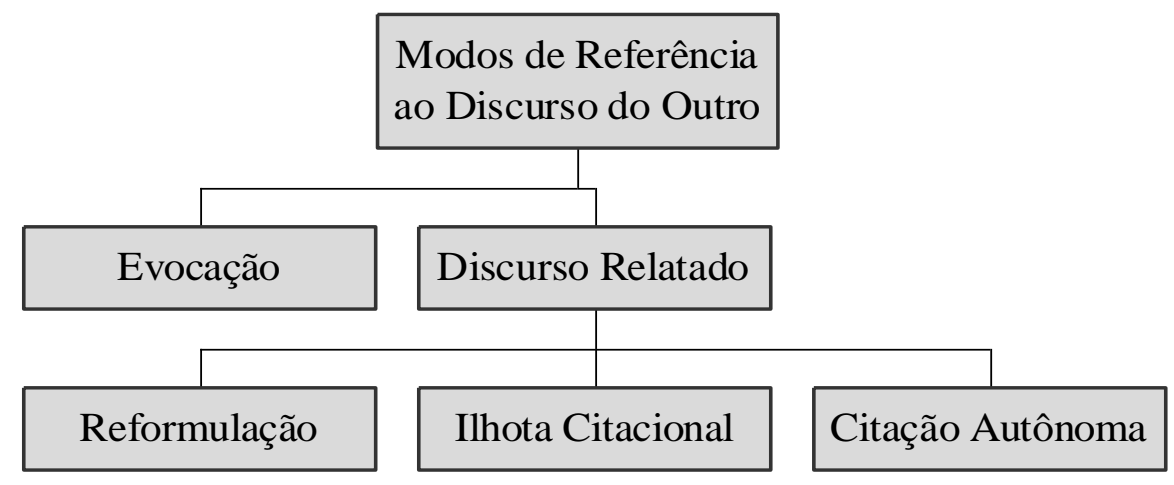

Esquema 1: Modos de referência ao discurso do outro.

Conforme proposto por estes autores, tomaremos como modelo metodológico, neste artigo, as categorias que evidenciam o uso do discurso relatado, a saber: (i) a reformulação, a retomada do dito, integrada, do ponto de vista enunciativo e temático, ao dizer do autor; (ii) a ilhota citacional, procedimento através do qual os pontos de vista enunciativos se integram, embora a referência ao discurso do outro seja colocada em evidência por elementos gráficos (escriturais, nos termos dos autores), e (iii) a citação autônoma, mecanismo através do qual se cria uma relativa autonomia entre os pontos de vista enunciativos.

Ainda com base nesse estudo, vale destacar as funções que o discurso do outro pode assumir na escrita acadêmica. No trabalho desses autores, foi constatado que estudantes universitários e especialistas estabelecem funções diferentes ao utilizar a voz dos teóricos que respaldam a construção textual. O quadro abaixo aponta essas diferenças: 


\begin{tabular}{|c|c|}
\hline \multicolumn{2}{|c|}{ FUNCCOEES DO DISCURSO DO OUTRO } \\
\hline Em artigos de especialistas & Em relatórios de estudantes \\
\hline $\begin{array}{l}\text { * Introduzir seu ponto de vista ("Desde 1996, X } \\
\text { assinalava que..."). }\end{array}$ & * Fundamentar uma afirmação \\
\hline $\begin{array}{l}\text { * Marcar o pertencimento a uma corrente, a uma } \\
\text { escola ("Meu estudo se situa no quadro da } \\
\text { polifonia tal como foi desenvolvido por Oswaldo } \\
\text { Ducrot (1984)"). }\end{array}$ & * Introduzir seu ponto de vista \\
\hline $\begin{array}{l}\text { * Referir-se a trabalhos anteriores, para traçar o } \\
\text { estado de uma problemática, para sustentar uma } \\
\text { definição. }\end{array}$ & * Sustentar uma definição \\
\hline $\begin{array}{l}\text { * Fundamentar uma afirmação ("A compreensão } \\
\text { em leitura está ligada a automatização dos } \\
\text { processos de baixo nível (Fayol, 1998)"). }\end{array}$ & $\begin{array}{l}\text { * Justificar, não somente uma afirmação (como } \\
\text { fazem os especialistas, mas, sobretudo, um } \\
\text { comportamento. }\end{array}$ \\
\hline $\begin{array}{l}\text { * Discutir uma afirmação, se afastar de uma } \\
\text { posição ("Se se pode admitir, com D. Véronique, } \\
\text { que (...), o exemplo que o autor dá apresenta } \\
\text { alguns problemas(...)"). }\end{array}$ & * A introdução de uma idéia nova. \\
\hline
\end{tabular}

Quadro 1: Funções do discurso do outro

Conforme mostra o quadro comparativo acima, existem diferenças linguísticas e discursivas no que se refere à utilização do discurso do outro por parte de estudantes e por parte de especialistas. As funções acima elencadas nos permitem afirmar que a referência ao discurso do outro deve ser entendida como uma prática que requer do aluno escritor um mergulhar entre vozes e, caso isso não ocorra, o fato de submeter-se a um discurso citado pode significar somente uma apropriação sem "poder indicar, na escrita de estudantes, o conhecimento que se tem da área e a adesão ou não a determinado ponto de vista" (MATENCIO, 2003, p. 03).

\section{MODOS DE REFERÊNCIA AO DISCURSO DO OUTRO NOS CURSOS DE LETRAS E DIREITO}

A seguir, com base na análise da seção de fundamentação teórica das monografias que compõem o corpus desta pesquisa, apresentamos os resultados (por curso) dos diferentes modos de referência ao recurso do outro e, em seguida, 
tecemos alguns comentários a respeito dessas escolhas pelos alunos escritores dessas diferentes áreas (Direito e Psicologia). Nessa análise, após inúmeras leituras dos textos, quantificamos a ocorrência dos diferentes modos de referência ao discurso do outro, a partir da categorização de Boch e Grossmann (2002). Vejamos como se mostra tal ocorrência no curso de Direito:

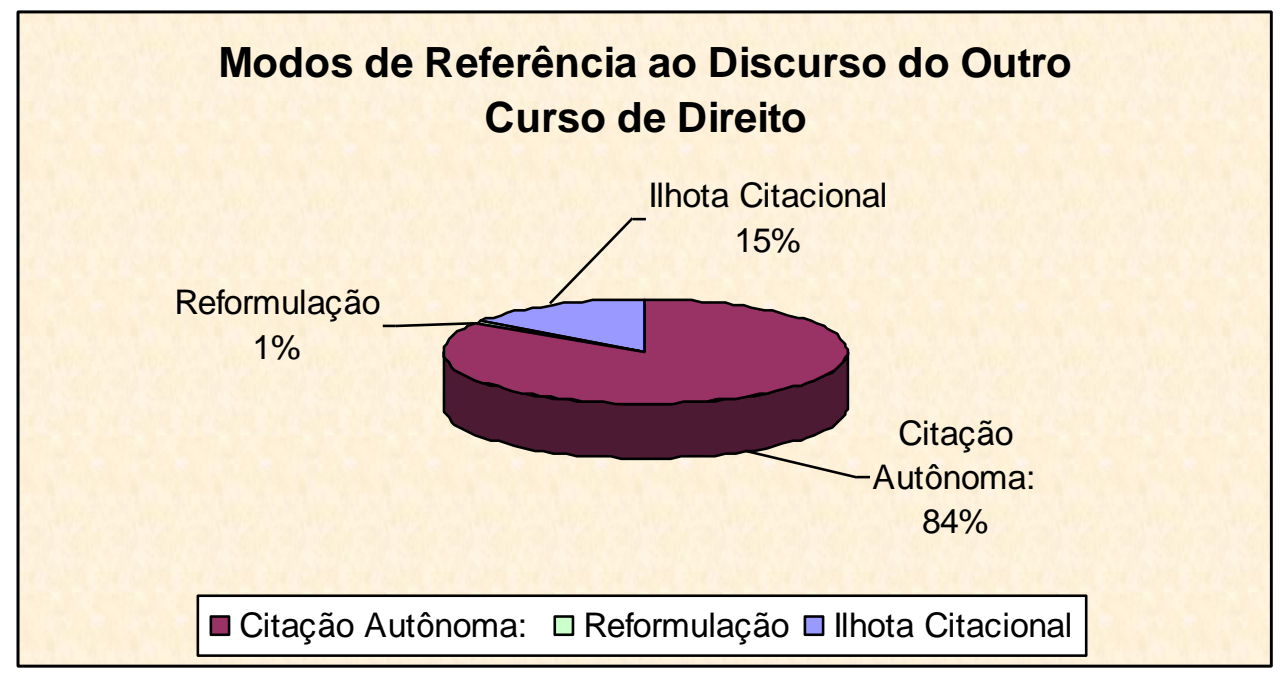

Gráfico 1: Modos de referência ao discurso do outro - Curso de Direito

A partir da análise das informações expostas no gráfico acima, podemos observar que, nas monografias de conclusão de curso da área de Direito, os alunos privilegiam sobremaneira o uso da citação autônoma, aqui entendida também como discurso direto (84\%). Tal fato pode indicar que os estudantes, por estarem iniciando seus contatos com a escrita acadêmica e pela pouca habilidade com outras formas de discurso, optam por manter um certo distanciamento com os textos dos teóricos estudados, evitando incorrerem em erros de reformulação. Outra evidência do uso da citação/discurso direto pode estar associada ao fato de que, durante a graduação e também na elaboração da monografia no final de curso, esses estudantes são frequentemente orientados pelos professores a apresentarem os conhecimentos construídos, sem deixarem, no entanto, de marcar as fontes com as quais dialogam.

Ainda nessa linha de raciocínio, o gráfico nos leva a considerar que, para esses estudantes, a citação autônoma representa a forma canônica de referência ao discurso do outro, uma vez que fornece modelos de estilo científico e possibilita, 
dentro dessa comunidade discursiva ${ }^{3}$, uma melhor fundamentação e valorização do dizer jurídico.

Por outro lado, a leitura de um percentual considerável de monografias que circulam na área de Direito nos revela um outro dado: a supervalorização da voz do outro e o apagamento, em muitas das vezes, da voz do sujeito escritor. Em outras palavras, não há, nessa área do conhecimento, um gerenciamento de vozes, mas um distanciamento discursivo entre o estudante de Direito e os "renomados" teóricos da área jurídica. O discurso de autoridade, trazido de maneira notória na forma de citações autônomas/discurso direto, parece evidenciar uma insegurança desses alunos frente aos pontos de vista dos autores dessa área.

Em vista disso, entende-se que os alunos escritores do curso de Direito apresentam dificuldades no momento de posicionar-se diante do texto em construção e, por essa razão, há, na escrita desses sujeitos, uma evidente sobreposição de ideias de outros autores, passando seu posicionamento quase que invisível diante desses teóricos. Assim, pode-se afirmar juntamente com Matencio e Silva (2003, p. 14) que esses alunos acabam se "ocultando sob a máscara do referente (autor/fonte)", isto é, sob o dito no texto retextualizado. O uso privilegiado dessas citações diretas indica, por exemplo, que há uma preocupação em conservar a integridade e a autenticidade do discurso citado, separando-o por meio de elementos linguísticos e/ou tipográficos. Isso mostra que, mais importante do que anunciar que um outro diz o que se retoma, valoriza-se o que o outro diz, sem que sua enunciação seja tematizada, cabendo ao aluno escritor o papel simplista de articulador do texto, ou seja, de alguém que se responsabiliza apenas pela organização e tessitura das vozes, apagando e/ou ocultando o papel principal de ser um sujeito retextualizador.

Nesse sentido, o fragmento abaixo ilustra a prática recorrente de citações diretas, consideravelmente extensas, ocupando, em alguns casos, a metade de uma

\footnotetext{
${ }^{3}$ A expressão "comunidade discursiva", utilizada inicialmente por John Swales (1990), é entendida aqui como relacionada à noção de gênero, referindo-se a um grupo que utiliza a língua em contextos específicos e de acordo com convenções pré-estabelecidas entre seus membros. Nesse sentido é que se pode falar em comunidade discursiva, referindo-se, por exemplo, ao curso de Direito ou ao curso de Psicologia.
} 
página, na escrita dos alunos do curso de Direito, evidenciando a dificuldade de posicionarem-se diante das vozes que se manifestam no texto.

Considerando as várias interpretações que possam explicar a palavra sucessão, faz-se necessário apresentar alguns conceitos para que se possa entender a matéria na sua integralidade. No dizer de Venosa:

Suceder é substituir, tomar o lugar de outrem no campo dos fenômenos jurídicos. Na sucessão, existe uma substituição do titular de um direito. Esse é o conceito amplo de sucessão no direito. Destarte, sempre que se uma pessoa tomar o lugar de outra em uma relação jurídica, há uma sucessão.

No tocante a este tema tem-se a explicação de Silvio Rodrigues que leciona:

A idéia de sucessão sugere, genericamente, a de transmissão de bens, pois implica a existência de um adquirente de valores, que substitui o antigo titular. Assim, em tese, a sucessão pode operar-se a título gratuito ou oneroso, inter vivos ou causa mortis. Todavia, quando se fala em direito das sucessões entende-se apenas a transmissão em decorrência de morte, excluindo-se, portanto, do alcance da expressão, a transmissão de bens por ato entre vivos.

O que o doutrinador mostra é que o direito das sucessões se apresenta como um conjunto de normas que disciplinam a transmissão do patrimônio de uma pessoa que faleceu a seus sucessores. Ainda neste contexto, assevera Washington:

Num sentido amplo, a palavra sucessão, significa o ato pelo qual uma pessoa toma o lugar de outra, investindo-se, a qualquer título, no todo ou em parte, nos direitos que lhe competiam. No direito das sucessões, entretanto, emprega-se o vocábulo num sentido mais estrito, para designar somente a transferência da herança, ou do legado, por morte de alguém, ao herdeiro ou legatário, seja lei, ou em virtude de testamento.

Quadro 2: Monografia - Curso de Direito

Em relação aos trabalhos do curso de Psicologia, encontramos o seguinte resultado quanto aos modos de materialização do discurso relatado:

\section{Modos de Referência ao Discurso do Outro Curso de Psicologia}

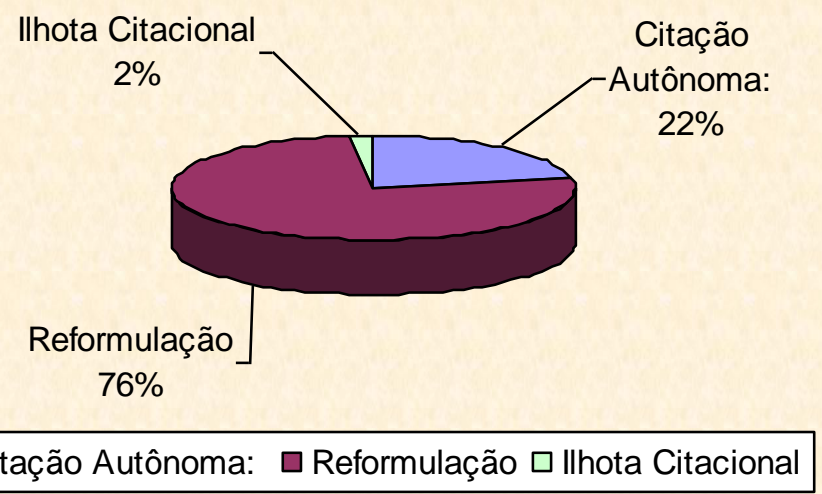

Gráfico 2: Modos de referência ao discurso do outro - Curso de Psicologia 
Nos textos dos alunos de Psicologia, diferentemente do que acontece no curso de Direito, a reformulação é a forma de discurso reportado que prevalece (76\% contra 1\%). Em seguida aparece a citação autônoma. A ilhota citacional apresenta-se de forma consideravelmente reduzida.

Segundo Boch \& Grossmann (2002), o recurso excessivo ao discurso do outro em forma de citação autônoma em textos acadêmicos de iniciantes (alunos de graduação) poderia relacionar-se à distância estabelecida entre pontos de vista enunciativos promovida pela citação, o que indicaria uma distância em relação às práticas acadêmico-científicas de produção de texto. No entanto, essa hipótese não se sustenta na análise das monografias de conclusão de curso por estudantes de Psicologia. Nessa área, privilegia-se o uso da reformulação como forma de reportarse às palavras do outro, o que, segundo esses autores pode evidenciar uma maior habilidade linguística por parte desses alunos. Contudo, isso não significa, a princípio, que a escrita acadêmica nessa área aponte para alunos mais experientes com a escrita acadêmica. O que houve, na verdade, foi apenas uma inversão do tipo de referência ao discurso reportado.

Outro fato curioso, presente nos textos desses alunos, diz respeito ao modo de introdução do discurso segundo por meio de citações autônomas/discurso direto. Em muitos casos, foi possível perceber a inexistência de marcas introdutórias desse fenômeno (citação direta), exceto pelo recurso único da paragrafação. Talvez esse fato possa estar em conformidade com as práticas discursivas dessa área do conhecimento, haja vista que as formas de transmissão do discurso do outro estão, de alguma forma, associadas ao contexto comunicativo em que emergem. 0 exemplo abaixo ilustra essa ocorrência:

“(...) Na contemporaneidade, tem-se diferentes maneiras de conceber a sexualidade de acordo com os atributos percebidos por cada mulher sobre os aspectos atrelados ao sexo, não se remetendo ao aspecto reprodutivo.

Sabemos que é na cama que verdadeiras batalhas pelo poder se travam. Enquanto uma mulher não possuir a liberdade de viver a sua sexualidade como desejar e da maneira como quiser e com quem for de seu interesse este planeta de animais racionais e irracionais em que homens usam a capacidade de pensar e raciocinar, mas não utilizam em favor da igualdade dos gêneros. (ROCHA, 2004, p. 26)"'”. 
Ainda neste contexto, foi possível verificar, também nas monografias do curso de Psicologia, uma sobreposição de citações sem que se estabeleçam entre elas comentários ou tomadas de posição por parte do aluno escritor. O que se quer dizer é que, em vista disso, parece haver uma dificuldade por parte desses estudantes de posicionarem-se diante de outras vozes, e, por essa razão, há em seus textos uma sobreposição de ideias de diversos autores, passando seu posicionamento quase que invisível diante desses teóricos. Dessa forma, esses alunos, conforme Matencio e Silva (2003) acabam se "ocultando sob a máscara do referente (autor/fonte)", isto é, sob o dito no texto retextualizado. Segue o exemplo, conforme abaixo:

Rebouças, Legay e Abelha (2007) comentam que satisfação no trabalho é o que se sente, resultante das características de cada um, dos valores e das expectativas com o ambiente de trabalho. Para eles, a satisfação pode interferir no comprometimento das suas atividades, criatividade, flexibilidade e da falta de comprometimento de ir além do exigido no trabalho.

De acordo com Ramos (1980) os objetivos que as pessoas pretendem obter são os aspectos que levam a pessoa a agir, e está ligado à conquista da satisfação. Esses fatores podem vir a colaborar para que os indivíduos possam alcançar mais prazer na sua atuação profissional e consequentemente satisfação no ambiente de trabalho.

Ramos (1980) afirma que para o funcionário se tornar mais experiente, é preciso que as organizações ofereçam condições para que esse funcionário adquira mais independência, e consequentemente maior controle e consciência sobre sí próprio. O mesmo autor comenta que o funcionário que se identifica com os objetivos da organização onde trabalha e é valorizado, terá desta forma maior produtividade na organização e estará satisfeito no trabalho que exerce.

Quadro 4: Monografia - Curso de Psicologia

\section{FUNÇÕES DO DISCURSO RELATADO NOS CURSOS DE DIREITO E PSICOLOGIA}

Conforme já explicitado anteriormente, focaremos aqui na análise sobre as funções do discurso do outro na escrita de estudantes concluintes do curso de Direito e de Psicologia, tendo por base o estudo comparativo realizado por Boch \& Grossmann (2002), o qual versa sobre a referência ao discurso do outro em textos de estudantes universitários e de especialistas. 
Vale ressaltar que o estudo desses autores tomou como objetos de análise dois corpora diferentes do ponto de vista do gênero textual, ou seja, artigos de pesquisa de especialistas e relatórios de estágio de alunos franceses universitários em fase de pré-profissionalização para o domínio do ensino. Levando-se em consideração esse último corpus, parece-nos possível fazer uma aproximação das funções do discurso relatado a que recorrem os estudantes franceses com as funções encontradas nas monografias analisadas neste artigo. Embora existam diferenças no tocante à mudança de gênero (de relatórios de estágio para monografias), a aproximação é, para nós, possível em razão das características presentes nesses diferentes gêneros, isto é, tanto para os estudantes franceses quanto para os brasileiros, tais gêneros propiciam uma iniciação à pesquisa e têm, como exigência, a necessidade de articular diferentes vozes teóricas.

Tendo como base as funções atribuídas ao discurso do outro por estudantes franceses ${ }^{4}$, retomaremos aqui as funções que julgamos mais recorrentes em nosso corpus, conforme análise dos textos monográficos produzidos por estudantes brasileiros dos cursos de Direito e de Psicologia, a saber:

1. Fundamentar uma afirmação: o aluno escritor lança mão do discurso do outro para fundamentar teoricamente as afirmações e/ou declarações expressas no texto.

2. Sustentar uma definição: o aluno escritor traz para a materialidade do texto as palavras de um especialista ou de uma autoridade na área com o objetivo de definir um conceito, ideia ou teoria.

Quadro 5: Funções do discurso do outro - cursos de Direito e Psicologia

O gráfico abaixo ilustra as ocorrências das funções do discurso do outro nas diferentes áreas:

\footnotetext{
${ }^{4}$ Conforme quadro 1, denominado "Funções do discurso do outro", o qual se encontra na página 07 deste artigo.
} 


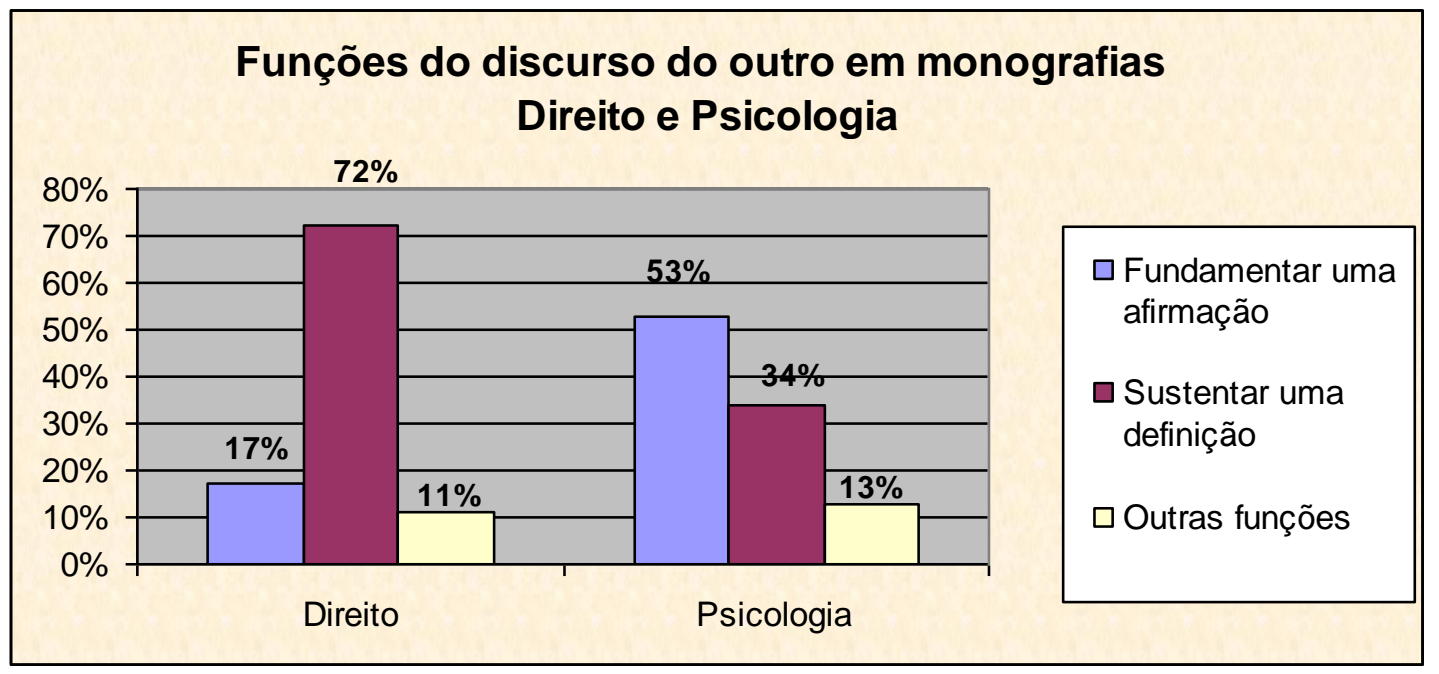

Gráfico 3: Funções do discurso do outro - cursos de Direito e Psicologia

Do que foi dito até o momento sobre a manifestação de outras vozes no texto monográfico, verificou-se que os estudantes de Direito e de Psicologia fazem uso do discurso reportado tanto para fundamentarem afirmações quanto para sustentarem definições. Vale salientar que, conforme evidencia o gráfico acima, na prática discursiva do curso de Direito privilegia-se a função de "sustentar uma definição", o que ocorre em 72 \%, seguida da função "fundamentar uma afirmação" com 17\%. Já nos textos monográficos de Psicologia, a função mais recorrente é "fundamentar uma afirmação" perfazendo um uso de 53\% e, em segundo lugar, a função de "sustentar uma definição" com 34\%. Esses números revelam diferenças quanto ao uso do discurso do outro nas diferentes áreas e indicam formas e modos distintos de discursivização por partes desses alunos. Os exemplos a seguir ilustram essas diferenças:

\section{Função 01 - Fundamentar uma afirmação}

A responsabilidade civil subjetiva decorre do dano causado pela ação culposa ou dolosa do agente. Por esta teoria, deverá a vítima fazer a ligação entre o dano e a culpa do agente causador deste dano, ou seja, deverá comprovar o nexo de causalidade. Sobre o assunto destaca Caio Mário:

A essência da responsabilidade subjetiva vai assentar, fundamentalmente, na pesquisa ou indagação de como o comportamento contribui para o prejuízo sofrido pela vítima. Assim procedendo, não considera apto a gerar o efeito ressarcitório um fato humano qualquer. Somente será gerador daquele efeito uma determinada conduta, que a ordem jurídica reveste de certos requisitos ou de certas características. 
A sexualidade da sociedade moderna é chamada por Giddens de sexualidade plástica, esta que teve
início no final do século XVIII, quando formas contraceptivas foram surgindo. Esta nova sexualidade
está atrelada a reinvidicação da mulher ao prazer sexual e a redução tendenciosa da família,
emancipando o 'relacionamento puro'. Sobre isto Bozon (2004, p. 123) afirma que
$\begin{aligned} & \text { o casamento institucional definhou, o que, entretanto, não quer dizer que tenha desaparecido nem } \\ & \text { tornaram } \\ & \text { que a aspiração a formar um casal tenha declinado: os percursos sexuais, afetivos e conjugais se } \\ & \text { estável. }\end{aligned}$ Quadro 7: Monografia - curso de Psicologia

Nesses dois fragmentos, observamos que, tanto o aluno escritor do curso de Direito como também o do curso de Psicologia, de forma a fundamentar o seu dizer, reportam-se ao discurso de autores reconhecidos nessas respectivas áreas. No primeiro exemplo, o aluno do curso de Direito, a fim de dar maior sustentabilidade à afirmação de que a responsabilidade civil subjetiva decorre do dano causado pela ação culposa ou dolosa do agente e, portanto, cabe à vítima comprovar o nexo de causalidade, recorre às palavras de um autor/fonte, neste caso, o jurista Caio Mario, o qual autoriza, com suas palavras, a afirmação feita pelo aluno escritor.

Essa mesma estratégia de recurso à voz de uma autoridade manifesta-se também no exemplo extraído da seção de fundamentação teórica do texto monográfico do curso de Psicologia. Nesse excerto, o produtor do texto diz que uma nova forma de sexualidade está diretamente ligada à reivindicação da mulher ao prazer sexual e à redução da família. Logo em seguida, busca nas palavras de um autor/fonte da área de Psicologia o respaldo necessário para fundamentar a sua afirmação.

Diante dessas observações, foi possível perceber que a função de fundamentar uma afirmação faz-se presente na escrita desses alunos como uma necessidade que se impõe aos textos acadêmico-científicos de um modo geral, principalmente quando o produtor é um iniciante na produção científica, uma vez que este precisa do respaldo da autoridade da área para fundamentar o seu dizer. Verificou-se também que, no curso de Direito, essa função se materializa nos textos em forma de citação autônoma, geralmente introduzida por um verbo de elocução. Já no curso de Psicologia, há ocorrências mais evidentes dessa função por meio de 
reformulações, também construídas com o auxílio de um verbo introdutor do discurso do outro.

\section{Função 02 - Sustentar uma definição}

A palavra casamento está definida de diversas formas por nossos doutrinadores, senão vejamos: Para Silvio Rodrigues, a palavra casamento pode ser denominada da seguinte maneira:

de

Casamento é o contrato de direito de família que tem por fim promover a união do homem e da mulher, conformidade com a lei, a fim de regularem suas relações sexuais, cuidarem da prole comum e se prestarem mútua assistência.

O doutrinador Silvio Venosa vai mais longe, lecionando que:

O casamento é o centro do direito de família. Dele irradiam suas normas fundamentais. Sua importância, como negócio jurídico formal, vai desde as formalidades que antecedem sua celebração, passando pelo ato material de conclusão até os efeitos do negócio que deságuam nas relações entre os cônjuges, os deveres recíprocos, a criação e assistência material e espiritual recíproca e da prole etc.

Baseando-se assim nos conceitos acima expostos, pode-se afirmar que o casamento é a fonte primordial da família desde a antiguidade até os dias atuais.

Quadro 8: Monografia - curso de Direito

[...] saber quais os aspectos promotores de satisfação no ambiente de trabalho não é o mesmo que saber o que gera a motivação.

Kanaane (1995, p.19), destaca a distinção entre satisfação e motivação:

A satisfação pode estar vinculada a um desejo, necessidade ou impulso, sem que necessariamente corresponda a um motivo básico de conduta do trabalhador no respectivo local de trabalho. A motivação, por outro lado, corresponde às ações selecionadas pelo indivíduo na busca do alcance de suas necessidades, e é influenciada por fatores inerentes à personalidade individual e por aqueles oriundos do ambiente e da herança genética. O trabalhador pode estar satisfeito parcial ou até plenamente, sem que com isso tenha atingido o nível de realização pessoal ou profissional em dado contexto organizacional; contrariamente, pode ocorrer que a ação de enfrentar obstáculos organizacionais possa trazer-lhe satisfação e realização, à medida que ela esteja associada as expectativas e possibilidades percebidas pelos indivíduos.

Quadro 09: Monografia - curso de Psicologia

Nesses fragmentos, observa-se que os alunos escritores de Direito e de Psicologia reportam-se às palavras do outro por meio de citações autônomas, o que, num primeiro momento, já demonstra uma autonomia no plano enunciativo, ou seja, percebe-se uma distinção de vozes sobre as quais recai a responsabilidade pelo dito.

Nessa linha de raciocínio, ressalta-se que o objetivo maior dessa função é apresentar uma definição, conceito ou teoria de autoridades da área (autor/fonte) sobre a temática colocada em foco pelo aluno escritor. No primeiro exemplo, o aluno apresenta o conceito de casamento sob o ponto vista de Silvio Rodrigues e, 
na sequência, traz um conceito mais amplo de casamento defendido pelo doutrinador Silvio Venosa. Nos dois casos, os autores evocados apresentam uma definição sobre o conceito de casamento, contribuindo com o discurso citante, uma vez que tais definições são proferidas por que tem autoridade e reconhecimento legitimados para fazê-lo. No segundo exemplo, extraído do texto monográfico do curso de Psicologia, o aluno escritor faz uso da voz de um especialista na área (Kanaane, 1995), para esclarecer e, ao mesmo tempo, definir teoricamente a distinção entre satisfação e motivação no ambiente de trabalho.

Como se percebe, o ato de introduzir no texto definições proferidas por diferentes enunciadores é uma prática presente na escrita acadêmica dos cursos analisados. No entanto, vale destacar que é no curso de Direito que essa função ocorre com mais frequência e, na maioria absoluta das vezes, sob a forma de citação autônoma, podendo ser introduzida tanto por verbos de elocução quando por expressões preposicionais. O uso dessa função nos mostra que os alunos dessas comunidades discursivas atendem àquilo que prescrevem a grande maioria dos manuais de metodologia científica, ou seja, que a escrita acadêmica deve pautar-se numa ancoragem teórica, colocando, muitas das vezes, o estudante face a exigências contraditórias, isto é, citar, mas não muito, dar prova de originalidade, mas se referir permanentemente ao discurso do outro.

Outro ponto importante diz respeito ao fato de que, embora o discurso citado se materialize na escrita desses alunos, observa-se uma ausência de posicionamento e de imbricamento das vozes que perpassam a produção textual, o que, talvez, esteja relacionado à pretensão de uma escrita menos parcial e mais expositiva. Importante esclarecer que a predominância de uma ou outra função ou, ainda, a preferência por um modo $\mathrm{x}$ ou y de reportar-se às palavras de outrem indicam diferentes maneiras e possibilidades de discursivização, o que está diretamente ligado às práticas de textualização das diferentes áreas. 


\section{CONSIDERAÇÕES FINAIS}

A análise realizada parece demonstrar que, além das diferenças identitárias atribuídas aos cursos analisados, os alunos escritores dessas diferentes áreas apresentam certas dificuldades no que diz respeito à identificação de funções precisas para as possíveis formas de manifestação do discurso reportado e, também, para com a articulação de vozes discursivas nos textos produzidos. Essa constatação pode estar associada ao fato de que, esses alunos, oriundos de uma prática escolar que, sistematicamente, tem valorizado um padrão de escrita em que se privilegia o dito e a simples informação em detrimento do jogo enunciativo de marcar pontos de vista, não conseguem estabelecer nos textos monográficos um diálogo consistente entre o discurso citante e o discurso citado.

Diante do exposto, vale assinalar que os usos linguísticos, os modos e as funções do discurso relatado nas diferentes comunidades discursivas, ao mesmo tempo em que são marcados por necessidades de padronização e de maior habilidade na escrita acadêmica, representam valores assumidos e compartilhados, construindo, portanto, a identidade social desses alunos. Em outros termos, conforme Dias (2005, p. 04), ainda no interior de um mesmo domínio discursivo como o acadêmico -, pode haver peculiaridades desse uso, tendo em vista os valores que são construídos e engrendados no interior das práticas discursivas de cada curso e, por isso, as posições identitárias assumidas, de alguma forma, pelos alunos escritores.

Como já reiterado, no que diz respeito ao fato de esses estudantes reportarem o discurso segundo sempre como uma "voz de autoridade", vale destacar as palavras de Maingueneau (1997), pois, segundo ele, os valores residem em cada formação discursiva, uma vez que o sujeito enuncia a partir de um lugar definido e, em muitas vezes, não cita quem deseja ou como deseja, mas de acordo com as imposições desse lugar discursivo, o qual regula os modos de referir-se ao discurso do outro.

Nessa linha de raciocínio, o que se quer dizer é que as condições de produção e funcionamento dos textos que circulam nos cursos aqui analisados 
acabam por legitimar, de alguma forma, as ações de linguagem que lhes são próprias, como também caracterizam sua identidade. Em outras palavras, o modo de discursivização reflete a ação do sujeito bem como de sua comunidade discursiva, o que pode revelar diferentes práticas sociais de escrita e, também, seus posicionamentos identitários.

Finalizando, é possível estabelecer uma relação entre a análise efetuada e a atividade de revisão de textos, mais especificamente com a revisão de textos de cunho acadêmico-científico. O exercício de revisão textual dos gêneros produzidos na academia exige conhecimentos que ultrapassem uma visão de linguagem como mero código e que considere, além da sistematicidade e da forma, a dimensão polifônica e discursiva dessa escrita. Em outras palavras, exige a capacidade de reconhecer, por exemplo, que os diferentes modos e funções de referência ao discurso do outro podem provocar, na materialidade textual, efeitos de sentido diversos e, ainda, caracterizar posições identitárias do sujeito escritor em um campo discursivo, seja frente aos modelos de "saber dizer" legitimados e compartilhados pelo discurso citado, seja frente aos sistemas de valor da comunidade discursiva a que pertence. Desse modo, soma-se à qualificação do revisor a habilidade de leitura diferenciada e especializada, capaz de considerar, além de aspectos linguísticos e gramaticais, a dimensão enunciativo-discursiva da escrita acadêmica, considerando as diferentes vozes sociais que se materializam na sua produção.

\section{REFERÊNCIAS}

ANDRADE, M. M. de. Introdução à metodologia do trabalho científico: elaboração de trabalhos na graduação. 5 ed. São Paulo: Atlas, 2001.

BENITES, Sônia A. L. Contando e fazendo a história: a citação no discurso jornalístico. São Paulo: Artes \& Ciência, 2002.

BENVENISTE, Émile. Problemas de Linguística Geral II. Trad. Eduardo Guimarães et alli. São Paulo: Pontes, 2006. (Original de 1966). 
BOCH, F.; GROSSMANN, F. Referir-se ao discurso do outro: alguns elementos de comparação entre especialistas e principiantes. Scripta, Belo Horizonte, v. 6, 2002.

BRONCKART, Jean Paul. Atividade de Linguagem, textos e discursos: por um interacionismo sócio-discursivo. Trad. Anna Raquel Machado e Péricles Cunha. São Paulo: EDUC, 1999.

DIAS, D. L. O recurso ao discurso do outro como forma de posição identitária. Scripta, Belo Horizonte, v. 7, 2005.

DUCROT, Oswald. O Dizer e o dito. Trad. Eduardo Guimarães. Campinas, São Paulo: Pontes, 1987.

LAKATOS, Eva M.; MARCONI, Marina de A. Metodologia do Trabalho Científico. 4 ed. São Paulo: Atlas, 1992.

MACHADO, Ana Raquel et alli. Resenha. São Paulo: Parábola, 2004.

MACHADO, Ana Raquel et alli. Planejar gêneros acadêmicos. São Paulo: Parábola, 2005.

MAINGUENEAU, Dominique. Novas tendências em análise do discurso. 3 ed. Trad. Freda Indursky. São Paulo: Pontes, 1997.

MAINGUENEAU, Dominique. Análise de Textos de Comunicação. Trad. Cecília P. de Souza e Silva e Décio Rocha. São Paulo: Cortez, 2001.

MATENCIO, Maria de Lourdes Meirelles. Referenciação e Retextualização de textos acadêmicos. Um estudo do resumo e da resenha. ANAIS do III Congresso da ABRALIN. Rio de Janeiro: UFRJ, 2003. p. 1-10.

MATENCIO, Maria de Lourdes Meirelles. Atividades de Retextualização em práticas acadêmicas: um estudo do resumo. Scripta, Belo Horizonte, v. 6, 2002.

MATENCIO, Maria de Lourdes Meirelles. O recurso do discurso do outro em textos de alunos de Letras. Texto-base apresentado no $14^{\circ}$ inPLA, 2004.

MATENCIO, Maria de Lourdes Meirelles; SILVA, Jane Quintiliano Guimarães. Retextualização; movimentos de aprendizagem. II Encontro Internacional Linguagem, Cultura e Cognição. Belo Horizonte/Campinas: Faculdade de Educação da UFMG/Faculdade de Educação da UNICAMP, 2003.

MOTTA-ROTH, D. (Org.) Redação acadêmica: princípios básicos. Santa Maria: Universidade Federal de Santa Maria, Imprensa Universitária, 2001.

NUNES, L. A .R. Manual da Monografia: como se faz uma dissertação, uma tese. São Paulo: Saraiva, 2001.

SIMÔES, D. M. P. A produção de textos acadêmicos. In: HENRIQUES, C. C. (Orgs.). A redação de trabalhos acadêmicos: teoria e prática. Rio de Janeiro: Ed. da UERJ, 2002. 